\title{
Teaching Chemistry in Rural America: A Comparative Study Examining Innovative Informal Education and Applied Science Approaches to Improving Engagement
}

\author{
Running Heading: Teaching Chemistry in Rural America
}

\author{
Gregory Van Doren \\ University of Alaska Fairbanks \\ United States \\ E-mail: drgsvd@gmail.com \\ Lawrence Kevin Duffy (Corresponding author) \\ University of Alaska Fairbanks \\ United States \\ E-mail: lkduffy@alaska.edu
}

Received: June 16, 2016 Accepted: July 19, 2016 Published: August 29, 2016

doi:10.5296/ire.v4i2.9537～URL: http://dx.doi.org/10.5296/ire.v4i2.9537

\begin{abstract}
How to engage underrepresented students in Science and Engineering careers is an important challenge in most rural areas. A formal school environment is not always the best place to learn for many students. Informal, place-based, culturally relevant and applied Science education can be used to engage many students commonly bypassed by formal lecture approaches. Integration of traditional "western" Science with traditional local culture has been proposed to increase engagement and broaden the participation of rural students in Science courses. Principles of chemistry such as colors and dyes were taught in both standard University classes and community workshops. Participant self-assessments were compared with self-assessments of students in introductory chemistry courses at two Universities. The formal course data correlated prior knowledge of content to increased learning gains for basic
\end{abstract}


chemistry concepts. The community workshop participant responses differed with those of formal University students, indicating both location and context of the presentation as factors in engagement. When held in a University classroom and laboratory, where ideas were not related to local cultures and places, learning outcomes were lower in applied knowledge compared to workshops held at a cultural center. A long-term commitment to informal Science education in a community setting is a promising approach to improving diversity in the Science workforce by using applied Science topics and cultural relevance to teach basic concepts.

Keywords: applied science education, chemistry, cultural engagement, place-based education, traditional knowledge

\section{Introduction}

In undergraduate Chemistry courses, especially those courses for non-Science majors, the problem of connecting the courses with the learning needs of the students has been well documented (NAS, 1998; 2012). The lack of engagement with Science principles needed to understand and live in a modern technological society impacts the learning for many students, especially women and minorities (Rich, 2011; Wildcat, 2009). Chemistry can be embedded in a holistic exploration of broader, real-world social and political issues where students, as citizens, can see a connection to their job or community (Duffy et al., 2011; NAS, 2014). Without place-based and cultural engagements, we are less likely to connect to the students, resulting in reduced learning outcomes (Barnhardt, 2002; Barnhardt \& Kawagley, 2003; Nicholas-Figueroa et al., 2015).

In the last century, Indigenous knowledge and western Science were viewed as two independent systems (Barnhardt, 2002; Lowan-Trudeau, 2013; Medin \& Bang, 2014). Generally, western Science is transmitted through literature and formal courses in the classroom while indigenous or traditional knowledge is communicated informally through observation, experiences and stories (Mazzocchi, 2006; Nakashuma \& Roue,2002). Lowan-Trudeau $(2012,2013)$ has pointed out the tensions between western and Indigenous Science that has researchers such as Cajete, Wildcat, Kawagley and Barnhardt searching for common ground (Nicholas-Figueroa et al., 2015). Informal education with a land and cultural perspective could be a setting for a curriculum of stories and place to engage students (Duffy, et al., 2011; Lowan-Trudeau, 2015).

Over the last 30 years, there have been major advances in developing methods to engage students (Sobel, 2004; Van Lopik, 2012). One such project, funded by the National Science Foundation, is SENCER, Science Education for New Civic Engagement and Responsibilities (Middlecamp et al., 2006; Burns, 2010). This national dissemination project strived to develop faculty who could engage students by using capacious real world issues in their Science, Technology, Engineering and Mathematics courses. SENCER courses connect Science and public interests by teaching through these complex issues in the local context of the student to the underlying principles (Middlecamp et al., 2006; Duffy et al., 2011). SENCER courses aim to build scientific literacy for participation in the social economic system. The more students can see relevance to their own everyday lives and to community, 
the better their understanding of the principles and their learning outcomes (Nicholas-Figueroa, 2015).

SENCER also developed a novel student assessment of learning gains tool, SENCER-SALG, to measure the students' perceptions of their progress. The SENCER-SALG was not intended to substitute for direct assessments used in formal classrooms, but in the absence of other assessments, the research studies suggested that SALG responses would provide evidence of learning gains and aid in redesign (http://salgsite.org/). This study examined the SENCER-SALG in learning environments both in and outside of University classrooms. The objectives for using the SENCER-SALG in Science classes and informall Science education activities were (a) to obtain correlative data through participant self-assessment of learning gains; (b) evaluate quantitative and qualitative data which could inform decisions to modify or change Science outreach and education activities; (c) demonstrate the instrument's versatility and effectiveness outside of formal University Science courses and classrooms.

In this study we compared Chemistry courses for non-Science majors from two Universities in different regions and settings of the USA. We documented the participants' self-assessments of their Science learning gains and their attitudes towards Chemistry within formal and informal learning environments. Informal learning environments are a characteristic of Informal education which is broadly defined as education outside the standard school lecture setting. The learning is through the engagement of experience and conversation and often tailored to the individual (Medin \& Bang, 2014). It encourages exploration and engagement. One goal was to examine participant responses for indications that the SENCER-SALG (Student Assessment of Learning Gains, 2014) could inform rural faculty of relative educational successes and failures, as they endeavor to adapt University Science to local community need.

\section{Methods}

\subsection{Survey}

With the exception of one community workshop, where computers were not available, participants drew numbers from a hat and entered pre/post responses on paper forms that had identifying numbers. These responses were later entered into the SALG website (http://www.salgsite.org/). The website automatically calculated means, sitandard deviations, modes and generated graphs of the data, which provided an easy-to-read overview, with data variance depicted as error bars about the means. Individual responses could be singled out from group data, if desired; for instance, if a respondent marked the same response to every question, that data could be singled out. Surveys could be analyzed alone or combined with other surveys into a composite sample. Both types of analysis were used in this report.

The analysis focused on student self-assessment of "understanding", one of the ten question-stems in the SENCER-SALG and the first question-stem of the pre-course survey. Students were asked questions about their understanding of dyes and pigments, $\mathrm{pH}$, the Periodic Table of the Elements, balancing equations. There were 15 questions in all. The 


\section{Ml Macrothink}

International Research in Education

ISSN 2327-5499

2016, Vol. 4, No. 2

Lichert scale response options to the statement, "Presently, I understand..." were 1: Not observed/ applicable; 2: Not at all; 3: Just a little; 4: Somewhat; 5: A lot; 6: A great deal.

This SENCER pre and post experience rubric is similar to an individual audit of perceived learning gains. Every student makes a qualitative assessment of their knowledge and understanding of the question or issue posed. The instructors can view the summation of the student gains as none (scale 1 or 2); basic (scale 3 or 4); advanced (scale 5) or transformational (scale 6). Transformational indicates a higher quality of learning where the student can see broader concepts and relationships. The SALG assessment instrument does not identify individual students and automatically calculates means and standard deviations and generates graphics of the data. The Student t-test was used to compare pre and post survey means.

\subsection{Courses}

UAF Chem 100 was a course for non-Science majors and utilized the American Chemical Society's text Chemistry in Context (ACS, 2014), an issues-based text that had previously been combined with traditional knowledge, to engage students in Science (Duffy et al., 2009). The UAF instructor had prior experience using the SENCER-SALG. Thirty of the students enrolled in either the Spring or Fall 2009 UAF Chem 100 courses voluntarily completed the pre-course surveys (Table 1). The two UAF Chem 100 course surveys (two combined semesters of pre-and post-course responses) served as a control group, representing before/after attitudes and self-assessments from students who had no interaction with this study, other than completing the SENCER-SALG surveys.

Table 1. Student groups with both pre-course/workshop and post course/workshop surveys

1. UAF Chem 100 students (Spring and Fall 2009 semesters), who participated in the SENCER-SALG surveys. The students did not discuss traditionall Native American knowledge, related to dyes and pigments in the course.

2. HU Chem 101 students (Spring 2009 semester), who completed laboratory sessions using natural dyes, but who received no instruction relating naturall dyes to traditional Native American knowledge, nor did they participate in any class discussions about Native American cultures.

3. A 3-hour workshop for advanced placement high school Biology and Chemistry students, in which natural dyes were used to teach concepts related to $\mathrm{pH}$. At the workshop, a Yakama elder described why were important to Native Americans and also taught students Sahaptin names for the colors.

4. Two separate 6-hour dye workshops for Native American weavers; one also included several non-Native weavers and artists. Elders in attendance participated in $\mathrm{pH}$ experiments, and then they used dyed materials to demonstrate their weaving skills, told stories to others present, and assisted people with their weaving. 


\section{Macrothink}

International Research in Education

ISSN 2327-5499

2016, Vol. 4, No. 2

Student STEM course enrollment at the University of Alaska Fairbanks followed the usual demographics of under 7\% Alaska Natives and American Indians while at Heritage University, the percentage of American Indians enrolled in STEM courses was higher. UAF courses were held in a large amphitheater in the Reichardt Natural Science Building in Fairbanks, Alaska. HU students and community participants received instruction at several sites: one was held at the Yakima Campus; one was held at the local high school and one workshop was held at the Tamastlikit Cultural Center in Pendleton, Oregon with weavers and artists.

\section{Results}

\subsection{University of Alaska Fairbanks, the Control Group}

UAF's Chem 100 course used a SENCER model course approach and the American Chemical Society textbook, Chemistry in Complex Systems. This course model and textbook is designed to connect Chemistry to real world issues and applied topics.

In the UAF Chem 100 pre-course survey, the lowest student responses were about dyes and pigments, which were not discussed in the course. They ranged from a mean of $1.8 \pm .46$ for "scientific names for dyes, pigments" to a mean of $2.5 \pm 1.04$ for the "importance of dyes and pigments to my culture". Twenty percent of the respondents indicated that dyes and pigments were not applicable to the course. Pre-course questions about their understanding of "The Periodic Table of the Elements" resulted in a mean of $3.9 \pm 1.22$ and "the chemistry term pH" with a mean $3.8 \pm 1.03$ (Figure 1). Those were the highest understanding levels recorded for UAF, showing a basic pre-course understanding of the $\mathrm{pH}$ concept.

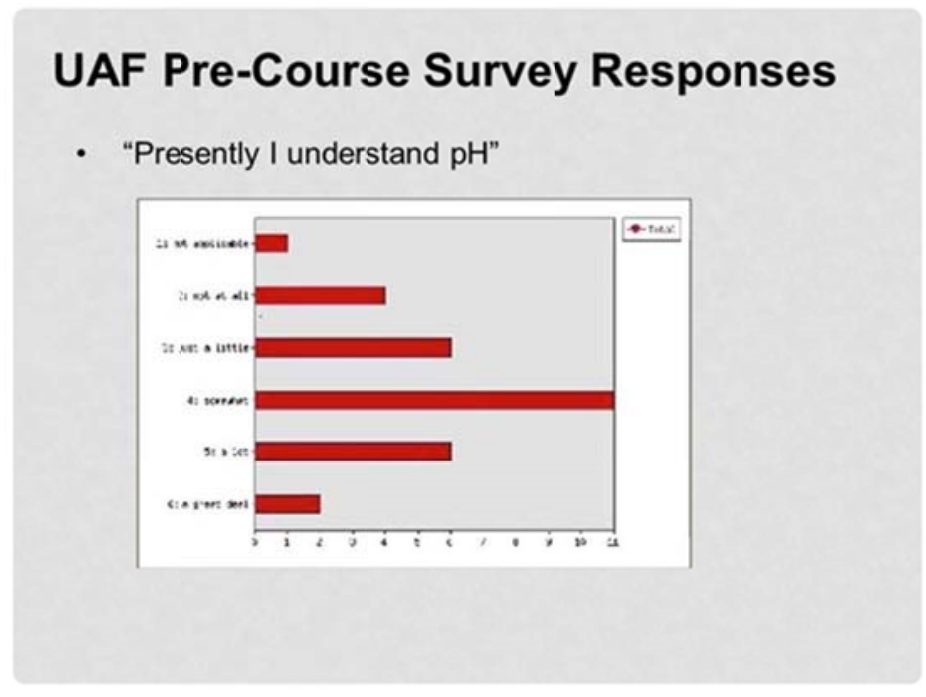

Figure 1. Pre-course survey indicates knowledge base

The post-course survey had 28 UAF students voluntarily completed responses. The numerical means of the pre-course and post-course surveys were not equivalent. The greatest post-course gain reported was "the Chemistry term $\mathrm{pH}$," with a mean of $4.4 \pm .96$ (good to 


\section{Macrothink}

great gain, Figure 2), followed by "how this course relates people to world issues," (Figure 3) $4.3 \pm 1.01$ (good gain) and "the Periodic Table of the Elements," $4.2 \pm .96$ (good gain).

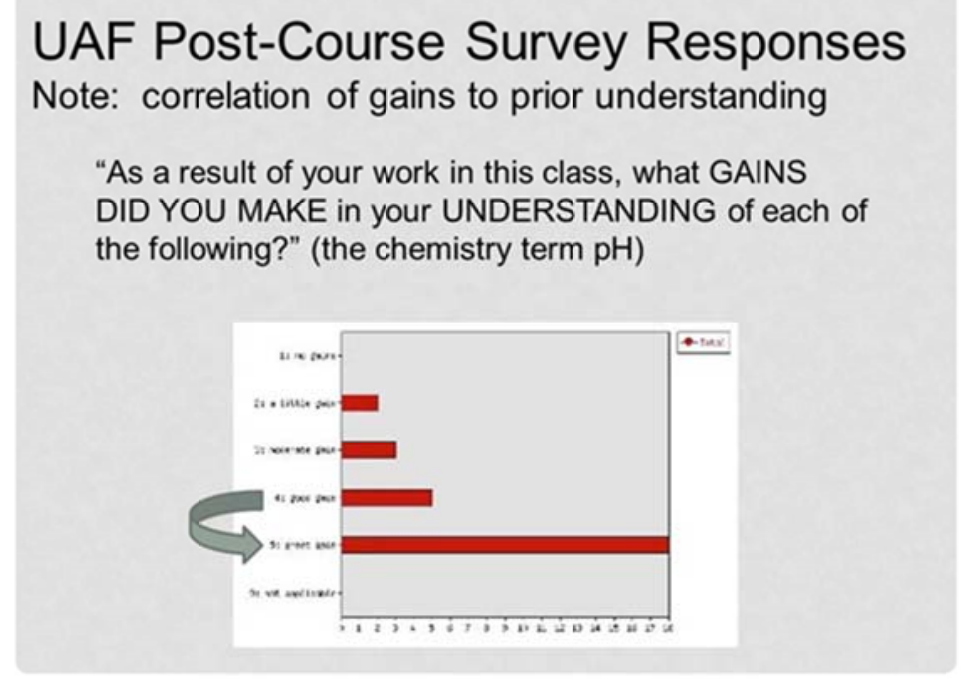

Figure 2. Post -course survey demonstrates knowledge gained beyond prior content exposure

As mentioned, the lowest gains reported were related to dyes for "the chemistry term mordant" with a mean of $2.4 \pm 1.3$ (a little gain) followed by "local or ethnic names for dyes and pigments, $2.6 \pm 1.36$ (little to moderate gain). Over one third (35\%) of the UAF students selected "not applicable" to the dye-related questions. Those responses were excluded from mean calculations. The use of the textbook and an Alaskan focus on the impact of climate change supports the concept that real world issues and related applied science can engage students and improve learning gains (Figure 3).

\section{The UAF Chem 100 course is an issues- based course, utilizing the text "Chemistry in Context"}

Response to: "how course relates people to world issues"

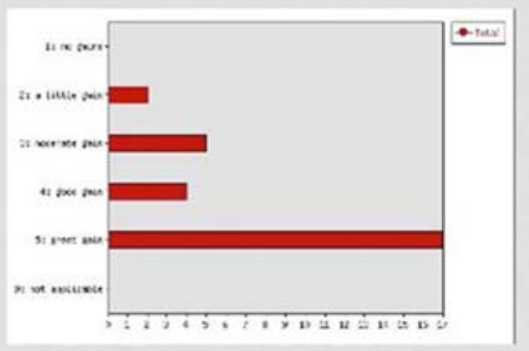

Figure 3. Applied science connects chemistry to real world issues 


\section{Macrothink}

\subsection{Heritage University}

The HU Chem 101 course was also for non-Science majors and the content was very similar to the UAF Chem 100 course. Unlike the UAF course, Timberlake's (2006) textbook was not an issues-based text such as the American Chemical Society's textbook, Chemistry in Context (ACS, 2014). The course clearly differed from the UAF course because natural dye laboratory experiments were substituted for standard $\mathrm{pH}$ and solution Chemistry lab experiments. The pre-course and post-course surveys were identical to those completed by UAF Chem 100 students. Twenty six students completed the pre-course survey and 20 completed the post-course survey. In the HU Chem 101 pre-course survey, the two lowest responses to "Presently I understand ..." were "the Chemistry term mordant" with a mean of $2.2 \pm .71$ (not at all) and "scientific names for dyes, pigments" with a mean of $2.2 \pm .59$ (not at all) with just under $10 \%$ of students marking "not applicable." The highest responses were for "The Periodic Table of Elements" with a mean of $3.8 \pm .75$ (just a little to somewhat) and "the Chemistry term $\mathrm{pH}$ " with a mean of $3.6 \pm 1.42$ (just a little to somewhat).

In the HU Chem 101 post-course survey, the two highest responses to the question "As a result of your work in this class, what GAINS DID YOU MAKE in your

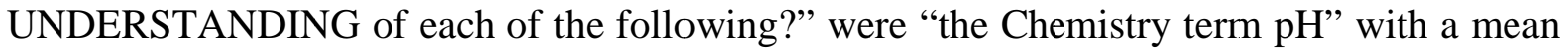
of $4.5 \pm .69$ (good to great gain) (Figure 4). "The Periodic Table of the Elements" also with mean of $4.5 \pm .69$ showed a good to great gain. Although responses included "Local or ethnic names for dyes and pigments" with a mean of $3.3 \pm .82$ (moderate gain) and "scientific names for dyes and pigments" with a mean of $3.5 \pm .90$ (moderate gain), the gains were still greater than the UAF results.

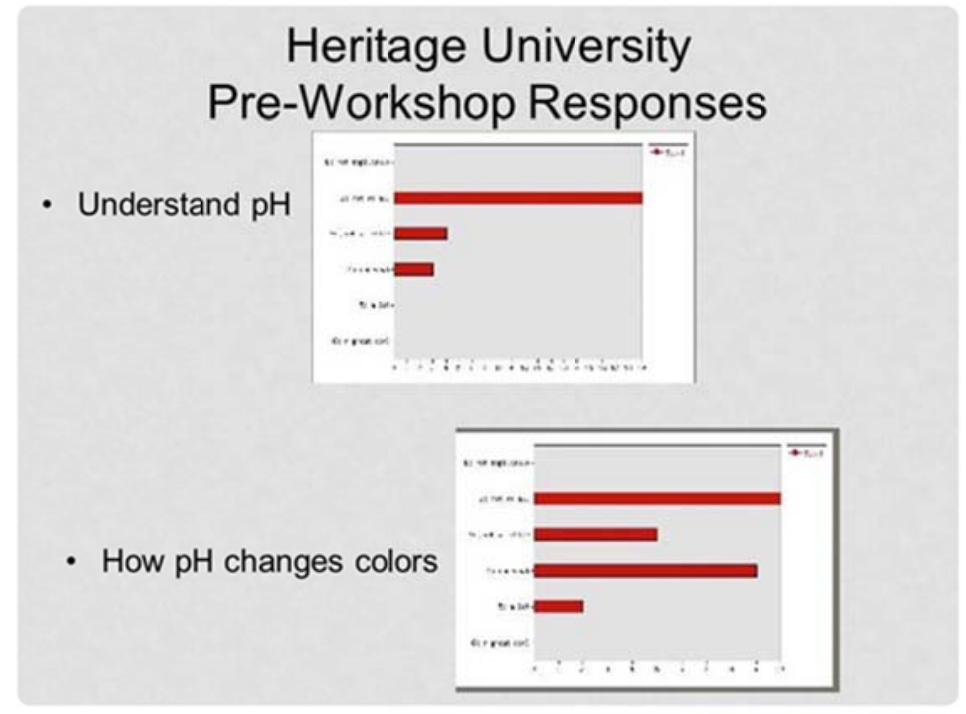

Figure 4. Heritage University students' understanding of $\mathrm{pH}$ prior to the workshop 


\subsection{Informal Education, High School Workshop}

For the high school workshop, in which 12 advancement placement Biology and Chemistry students participated, the pre-course survey of present understanding resulted in the lowest responses for "the Chemistry term mordant" with a mean of $1.9 \pm .29$ (not at all) and "scientific names for dyes and pigments" with a mean of $2.1 \pm .29$ (not at all), while the highest responses were for "The Periodic Table of Elements" with a mean of $4.4 \pm 1.42$ (a lot) and "Names of chemicals" with a mean of $4.4 \pm 1.51$ (somewhat to a lot). Responses to "the Chemistry term $\mathrm{pH}$ followed several other questions, with a mean of $3.3 \pm 1.15$ (just a little).

After the 3-hour workshop, the same students responded that their greatest gains in

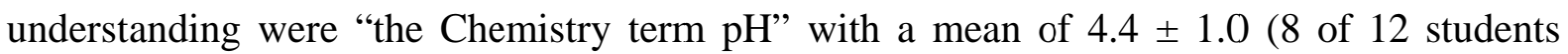
reported great gain," and "preparing materials for dyes and pigments” with a mean of 4.2 \pm .75 (good gain). Responses with the least gains reported were "how ideas in this class relate to other cultures" with a mean of $2.9 \pm 1.60$ (2 students responded "not applicable") and "how this course relates people to world issues" with a mean of $3.0 \pm 2.0$ (5 of the 12 students responded "not applicable”) while the remaining students reported moderate gains.

\subsection{Informal Education at the Tamastlikit Cultural Center}

A two-day, 6-hour workshop was held for weavers at the Tamastslikt Cultural Center, in Pendleton, Oregon. Over 20 weavers and artists attended, from three states, with several Native American elders among them. There were four participants, two of who were Native American, at a second workshop hosted at HU. Due to the small second group, workshop data sets were combined for analysis in this study.

In the pre-workshop surveys, the two lowest responses for understanding were "Native names for dyes, pigment and processes in using them” with a mean of $2.3 \pm .69 \mathrm{pH}$ (not at all) and "how $\mathrm{pH}$ and mordants change colors" with a mean of $2.4 \pm .70$ (not at all to just a little) while the highest response was "the importance of dyes and pigments to my culture" with a mean of $3.7 \pm 1.5$.

The post workshop survey had several high responses with means of 4.2 and standard deviations between 0.5 and 1.0: "differences between dyes and pigments", "how to obtain and extract natural dyes and pigments" (Figure 5) and "the importance of dyes and pigments to my culture". All reported good gains in understanding. By contrast in this group, the lowest response was "balancing equations" with a mean of $2.2 \pm 1.14$ (a little gain, with over $60 \%$ of participants reporting no gain or not applicable). 


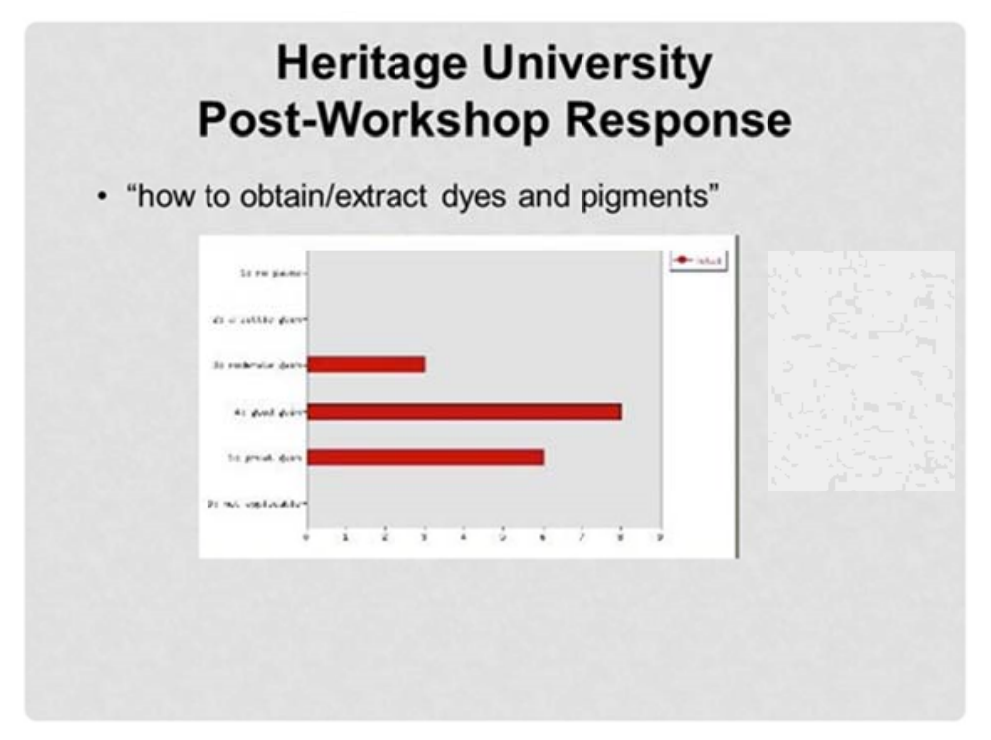

Figure 5. Cultural relationships improve students' learning gains

\section{Discussion}

\subsection{Prior Knowledge}

In both the UAF and HU introductory Chemistry courses for non-majors, students stated in the pre-course survey that "The Periodic Table of Elements" and the "Chemistry Term pH" represented their highest level of current understanding in Chemistry, although their responses were between "just a little" and "somewhat" levels. Notably, both UAF and HU students also claimed that their greatest gains in understanding occurred in those same two areas, with responses consistently in the "good” to "great gain” categories.

In this study's surveys, the students did not claim learning gains for content not included in the course; many UAF students either reported "no gain" or "not applicable" for questions related to dyes and pigments, which were not part of the UAF Chem 100 course. There were variations among responses, including a few students who reported learning gains for untaught content; however, the survey results were similar to those obtained by other SALG researchers where data support moderate correlations between direct assessment and the SALG, as reported on http://www.salgsite.org/

Learning to read the Periodic Table of Elements, beyond knowing the names of the elements and their atomic numbers, is one of the main course objectives in an introductory Chemistry course. The periodic table is based on how electron shells fill and determine an element's number of valence electrons which discern properties of groups of elements, their electron configurations and electronegativity's - all are essential to understanding ionic bonds, covalent bonds, chemical formulas and balanced reactions. These concepts are core knowledge requirements for other Science courses, but are presented from an abstract Western perspective, unconnected to the environment. Whether introductory students claimed to have prior understanding of the Periodic Table of the Elements, or not, it would be 
expected that post-course surveys would indicate gains in their understanding. It was not expected that they would necessarily be the highest gains recorded, however. Our observations would suggest that, for at least some UAF Chem 100 and HU Chem 101 students, prior knowledge and/or topic interest influenced the learning gains reported. When this knowledge was presented from a more applied, concrete issue basied perspective (by either the textbook or the instructor), the basic prior understanding was increased. The unanswered question would be how much more would these students be able to learn the next time they approached the subject, if either their interests were piqued or their partial learning became the prior knowledge base needed to excel the second time through? Both the UAF and HU formal class students had a focus on increased content acquisition because of the setting in contrast to the informal workshop weavers whose interest was only in the applied use of dyes.

At $\mathrm{HU}$, the pigment and dye laboratory experiments were primarily designed to teach concepts related to $\mathrm{pH}$, which is one of the last subjects addressed in a one-semester introductory Chemistry course for non-majors. Student performance, on direct assessment exams, was no better or worse than student performance in prior Semesters, when the experiments from a standard lab manual had been used. Whether or not students learned $\mathrm{pH}$ from the lecture, a standard $\mathrm{pH}$ lab, or the dye labs, they consistently reported "good gain" to "great gain" on the post-course surveys at both HU and UAF, when asked about their understanding of $\mathrm{pH}$. This indicates that the instructors' role communicating a connectivity of the chemistry concept to the student is important.

\subsection{Informal Education at Workshops}

At the beginning of the workshop at the high school lab, for the advanced placement high school students, the students had not yet begun the unit on $\mathrm{pH}$ in their classes, so their understanding of "the Chemistry term $\mathrm{pH}$ " was not among their top pre workshop responses. The post-workshop survey showed that 8 of the 12 students reported "great gain" for

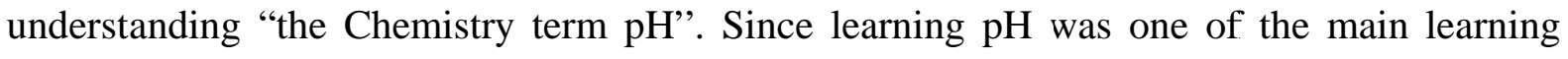
objectives of the workshop, the workshop would be traditionally viewed as a success. Informal workshops have been known to increase engagement and attention among students, leading to a feeling of concept understanding.

The advanced placement high school students had an unusually high self-assessment of their understanding of "the Periodic Table of Elements" in the pre-workshop survey (4.8, a lot). Nearly half of the high school students focused their attention directly on the laboratory $\mathrm{pH}$ experiments. Although a Yakama elder was present to describe the importance of dyes to his culture, and taught the students Sahaptin names for the colors extracted, their lowest post-workshop responses were for "how ideas in this class relate to other cultures" and "how this course relates people to world issues," with over $40 \%$ of the respondents claiming that those ideas were "not applicable”. For them, it was as if the Yakama elders' presence and the discussion "dye use in my culture" never occurred. This was unexpected, based on the literature (Medin \& Bang, 2014). 
In the Native American workshops at the Tamastslikt Center, the pre-course surveys, as in the University student groups, the highest response for understanding was "the Chemistry term $\mathrm{pH}$ ”, but unlike any other group there was also a high level of understanding of "the importance of dyes and pigments to my culture." In fact, the bimodal distribution of responses (8 responded "a lot" or "a great deal" and 8 responded "not at all”) directly reflected the cultural differences between the Native American elders and non-Native artisans attending the workshop. The lowest responses were "Native names for dyes and processes using them" and "how $\mathrm{pH}$ and mordants change colors." These responses likely reflected the non-Native's lack of interest in learning about Native names for dyes and processes and the Native American's lack of interest in learning about $\mathrm{pH}$ and mordant effects on color. In a negative way, this result demonstrates that perspectives will vary with the individual students. This has great implications for formal science courses where the drive is to increase class size with a "one size fits all" model. Our research indicates that individual perspective is a key part of connectivity and engagement. This is easier to accomplish in an informal setting.

In the Native American post-workshop survey, the highest gains were reported for "the importance of dyes and pigments to my culture" and "how to obtain and extract dyes and pigments”. As in every other pre/post survey, the highest pre-workshop understandings directly correlated to the highest gains reported in the post-workshop survey, with the exception of "the Chemistry term $\mathrm{pH}$." Although $\mathrm{pH}$ was the concept taught in the workshop, it was the application of the concept (using $\mathrm{pH}$ to change colors) that resulted in "how to obtain and extract dyes and pigments" being one of the highest gains in the post-workshop survey.

In the Native American workshop surveys, $50-60 \%$ of the participants reported "no gains" or "not applicable" to questions asked about content not included in the workshop (balancing equations, names of elements and compounds), indicating a correlation between their survey responses and actual knowledge presented, as compared to the University course surveys. When compared to the high school workshop responses, the Native American workshop responses, in the pre-course survey, did not show inflated estimates of understanding. The correctly marked "no gains" and "not applicable" responses in the post-course survey (for content that was not taught, but purposely included in the survey) were the highest for any group. These responses reflect more mature self-assessment of undersitanding needs and veracity in reporting learning gains and perhaps the lack of grade risk or classroom social pressures.

\subsection{Learning Environment}

The informal workshop setting used in this study gives an indication that learning environments had a large influence upon the participants' focus. In the high school workshop, a modern Chemistry laboratory environment directed participant focus towards the experiment at-hand, such that many students failed to see a connection between the dye experiment and other cultures, even when a Yakama elder described the connection. Contrastingly, the group at the Tamastlikt Cultural Center focused primarily on integrating new knowledge into their existing world views and values. In terms of learning theories, the 
high school workshop survey responses more closely resembled the "knowledge in pieces" or academic fragmentation theories, while the Tamastlikt workshop survey responses resembled the holistic views described by Cajete (2000) and Wildcat (2009), most likely based on the perspective of the weavers and artists.

While $\mathrm{pH}$ was taught the same way in both the high school and the workshops, the learning environment and cultural differences resulted in vastly different outcomes, because the learner had very different "needs" for the knowledge. While the quantitative data provided a substantial amount of information, the participants' written responses revealed much more qualitative information. Representative responses, from each course, reflected not only the differences in learning environments, but also differences among individuals, within those environments. Responses varied substantially, within the same course and between courses. For example, to the question "Please comment on HOW YOUR UNDERSTANDING OF THE SUBJECT HAS CHANGED as a result of this class/workshop" the following responses were recorded.

- "Appreciate our world and the materials provided us and how we can use them" (Tamastlikt Workshop)”;

- “Now I see how changing pH levels can affect outcomes” (Tamastlikt Workshop)”.

In the high school workshop, held in a University laboratory, a Yakama elder described the importance of the dyes and pigments to Yakama culture and helped students learn Sahaptin names for the colors extracted. Post-course surveys indicated that nearly half the students still did not associate any of the laboratory activities with culture or world issues, such as genetic engineering of food or safe drinking water. In the Tamastlikt Cultural Center workshop, participants accurately separated taught/non-taught items on the survey and described direct correlations between the subject taught and their culture. The courses and workshops taught in the laboratory setting were distinguished from the workshop taught in a cultural setting. In the laboratory setting, learning gains were associated with Chemistry content while in the cultural setting, learning gains were associated with traditional knowledge and culture. In the UAF course, the textbook content was related to applying Science to real world issues. The HU laboratory course and high school workshop responses did not emphasize practical applications of Chemistry or Chemistry relations to culture. Only the cultural center workshop's learning gains indicated an integration of new Chemistry knowledge into participants' practices, worldviews and values.

One of the greatest values of the SENCER-SALG is the ability to collect evidence and measure higher quantities of evidence (Hoffman et al., 2013). By evaluating the reactions of people, educational strategies can be improved before negative attitudes and diminished aspirations prevent "learning” changes. Educational zeal often circumvents students' reactions to educational programs, at the risk of compromising or preventing the holistic higher levels of knowledge acquisition and comprehension. Our SALG data on the workshop site illustrates how the evidence informed us. 


\section{Conclusion}

The SENCER-SALG described learning gains in two University chemistry courses for non-majors, a high school workshop and a Native American workshop. In all but the Native American workshop, the greatest learning gains in the post-course survey were highly correlated to the pre course claims of topic understanding in the pre-course survey, supporting earlier literature that prior knowledge of content can increase learning gains for similar Chemistry content. A textbook with an Earth Science perspective builds on the students' prior knowledge by presenting topics from a more rational perspective. We also concluded that, if possible, a Chemistry course should be taught within an appropriate cultural setting. The prior knowledge of a chemical concept, the place-based cultural relevance and an appropriate educational site will contribute to improved student engagement and in turn learning.

\section{Acknowledgements}

We are grateful to the leadership and staff at Heritage University and the University of Alaska Fairbanks for supporting the inclusion of traditional ecological knowledge in STEM courses and the students who invested their time and effort in these courses. We also acknowledge the helpful discussions with Dr. Cathy Middlecamp and Ms. Linda Nicholas-Figueroa. This study was funded by the National Science Foundation through a CCLI National Dissemination Awards DUE-0455586, DUE-0632397, and NSF 1356766.

\section{References}

ACS (American Chemical Society) (2014): Chemistry in Context, McGraw Hill Education.

Barnhardt, R. (2002). Domestication of the Ivory Tower: Institutional Adaptation to Cultural Distance. Anthropology and Education Quarterly, 33(2), 238-249.

Barnhardt, R., \& Kawagley, A. (2003). Culture, Chaos and Complexity: Catalysts for Change in Indigenous Education. Cultural Survival Quarterly, 27(4), 59-64.

Burns, W. D. (2010). SENCER: Theory and Practice In: Science Education and Civil Engagement: The SENCER Approach (Sheardy, R.D., Ed.). ACS Symposium Series 1037, ACS Washington, D.C. (pp.1-23).

Cajeta, G. (1999). Native Science, Natural Laws of Interdependence. Clear Light Publishers, Santa Fe.

Duffy, L., Godduhn, A., Nicholas-Figueroa, L., Fabbri, C., Middlecamp, C., \& van Muelken, M. (2011). Engaging Students in Science Courses: Lessons of Change from the Arctic. Interchange. http://dx.doi.org/10.1007/s10780-011-9151-6

Duffy, L., Middlecamp, C., Godduhn, A., \& Fabbri, C. (2009). Using Culture, Policy and Traditional Knowledge to Improve Engagement in Science Courses. Amer. Journ. Applied Sciences, 6(8), 1560-1566.

Hoffman, T. et al. (2013). Evidence-Based Practice (2nd Edition), Elsevier. 


\section{Macrothink}

International Research in Education

ISSN 2327-5499

2016, Vol. 4, No. 2

Lowan-Trudeau, G. (2012). Expanding the Conversation: Further explorations into indigenous environmental science education theory, research and practice. Cultural Studies of Science Education, 7, 71-81. http://dx.doi.org/10.1007/s11422-012-9379-1.

Lowan-Trudeau, G. (2013): Indigenous Environmental Education Research in North America: A brief review. International Handbook of Research on Environmental Education, 404-408.

Lowan-Trudeau, G. (2015): Contemporary Studies in Environmental and Indigenous pedagogies: A curricula of stories and place. Environmental Education Research, 21(4), 652-653.

Mazzocchi, F. (2006): Western Science and Traditional Knowledge: Despite their variations, different forms of knowledge can learn from each other. EMBO Report. Science and Society Viewpoint 7 (5): 463-466. http://dx.doi.org/10.1038/sj.embor.7400693.

Medin, D. L., \& Bang, M. (2014). Who’s Asking? MIT Press.

Middlecamp, C., Jordan, T., Schacter, A., Lottridge, S., \& Oats, K. (2006). Chemistry, Society and Civic Engagement (part1): Uranium and American Indians. J. Chem. Educ., 83, 1308-1312.

Nakashima, D., \& Roué, M. (2002). Indigenous Knowledge, Peoples and Sustainable Practice. In Timmerman P (ed), Encyclopedia of global Environmental Change. 5: Social and Economic Dimensions of Global environmental change, 314-324. Chichester, UK: Wiley.

NAS. (1998). Transforming Undergraduate Education in Science. National Research Council, National Academy of Science Press, Washington, DC.

NAS. (2012). Discipline-based Education Research: Understanding and Improving Learning in Undergraduate Science and Engineering. National Research Council, National Academy of Science Press, Washington, DC.

NAS. (2014). Undergraduate Chemistry Education: A Workshop Summary. National Research Council, National Academy of Science Press, Washington, DC.

Nicholas-Figueroa, L., Barnhardt, R., Duffy, L., Dunlap, K., van Muelken, M., \& Middlecamp, C. (2015). Delivering Post-secondary STEM Education on the North Slope, Alaska: Resilience and Adaptation. International Research in Education, 3(2), 80-92.

Rich, N. (2011). Restoring Relationships: Indigenous Ways of Knowing Meet Undergraduate Environmental Studies and Science. Dissertation, Antioch University.

Sobel, D. (2004). Place-based Education: Connecting Classrooms and Communities. Great Barrington, Massachusetts, The Orion Society, 109 p.

Stephens, S. (2000). Handbook for Culturally Responsive Science Curriculum. Alaska Science Consortium and the Alaska Rural Systemic Initiative, Fairbanks, Alaska. 72 p.

Student Assessment of Learning Gains. (2014). Retrieved from http://www.salgsite.org 


\section{Macrothink}

International Research in Education

ISSN 2327-5499 2016, Vol. 4, No. 2

Timberlake, K. (2006). An Introduction to General, Organic and Biological Chemistry. Prentice Hall Publishers, New York.

Van Lopik, W. (2012). Traditional Ecological Knowledge in the Tribal College Classroom. Journ. Environ. Studies Sci. http://dx.doi.org/10.1007/s13412-012-0095-7

Wildcat, D. (2009). Red Alert! Saving the Planet with Indigenous Knowledge. Fulcrum Publishing, Golden.

\section{Copyright Disclaimer}

Copyright reserved by the authors.

This article is an open-access article distributed under the terms and conditions of the Creative Commons Attribution license (http://creativecommons.org/licenses/by/3.0/). 